University of Nebraska - Lincoln

DigitalCommons@University of Nebraska - Lincoln

9-2005

\title{
Rose productivity and physiological responses to different substrates for soil-less culture
}

C. Samartzidis

Mediterranean Agronomic Institute of Chania, Greece

Tala Awada

University of Nebraska - Lincoln, tawada2@unl.edu

E. Maloupa

NAGREF, Agricultural Research Centre of Macedonia and Thrace, Thessaloniki, Greece

K. Radoglou

NAGREF, Forest Research Institute, Thessaloniki, Greece

H.-I. A. Constantinidou

Aristotle University of Thessaloniki,

Follow this and additional works at: https://digitalcommons.unl.edu/natrespapers

Part of the Natural Resources and Conservation Commons

Samartzidis, C.; Awada, Tala; Maloupa, E.; Radoglou, K.; and Constantinidou, H.-I. A., "Rose productivity and physiological responses to different substrates for soil-less culture" (2005). Papers in Natural Resources. 198.

https://digitalcommons.unl.edu/natrespapers/198

This Article is brought to you for free and open access by the Natural Resources, School of at DigitalCommons@University of Nebraska - Lincoln. It has been accepted for inclusion in Papers in Natural Resources by an authorized administrator of DigitalCommons@University of Nebraska - Lincoln. 
Published in Scientia Horticulturae 106:2 (September 1, 2005), pp. 203-212;

doi: 10.1016/j.scienta.2005.02.020 Copyright (C 2005 Elsevier B.V. Used by permission.

Submitted March 25, 2004; revised January 21, 2005; accepted February 17, 2005;

published online April 7, 2005.

\title{
Rose productivity and physiological responses to different substrates for soil-less culture
}

\author{
C. Samartzidis, ${ }^{1}$ T. Awada, ${ }^{2}$ E. Maloupa, ${ }^{3}$ \\ K. Radoglou, ${ }^{4}$ and H.-I. A. Constantinidou ${ }^{5}$
}

1. Mediterranean Agronomic Institute of Chania, Alsylio Agrokipiou, 73100 Chania, Greece

2. School of Natural Resources, University of Nebraska-Lincoln,

12-D Plant Industry-0814, Lincoln, NE 68583, USA

3. NAGREF, Agricultural Research Centre of Macedonia and Thrace, 57001 Thermi-Thessaloniki, Greece

4. NAGREF, Forest Research Institute, Vassilika 57006, Thessaloniki, Greece

5. Department of Agriculture, Aristotle University of Thessaloniki, 54124 Thessaloniki, Greece

Corresponding author - H.-I. A. Constantinidou, tel 3023109986 31,

fax 3023103147 99, e-mail constad@agro.auth.gr

\begin{abstract}
Cultivation of roses in various soil-less media was studied with the aim to identify the optimum soil condition for rose production. Madelon roses grafted on rootstock of Rosa indica var. major were transplanted to polyethylene bags containing zeolite and perlite (at ratios of 25z:75p, 50z:50p, 75z:25p and 100z:0p, v/v) in a climate-controlled greenhouse. Net photosynthesis $\left(A_{\text {net }}\right)$, stomatal conductance $\left(g_{s}\right)$ and water use efficiency (WUE) of roses were followed for 5 months. Flower production and quality were recorded in three flowering flushes during a 5-month period. Analysis of variance of repeated measurements showed that even though the overall $A_{\text {net }}$ did not differ among treatments (average $18.7 \mu \mathrm{mol} \mathrm{m}^{-2} \mathrm{~s}^{-1}$ ), trends in $A_{\text {net }}$ seasonality for roses in 25z:75p substrate differed significantly from those in 50z:50p, 75z:25p or 100z:0p. Stomatal conductance did not show any significant seasonality or trends in response to substrate mixtures, averaging $0.89 \mathrm{~mol} \mathrm{~m}^{-2} \mathrm{~s}^{-1}$. Water use efficiency was significantly lower for roses in 25z:75p than in 100z:0p mixtures (1.8 \pm 0.15 and $2.0 \pm 0.13 \mu \mathrm{mol} \mathrm{m}^{-2} \mathrm{~s}^{-1} \mathrm{CO}_{2} /$ mmol m $\mathrm{m}^{-2} \mathrm{~s}^{-1} \mathrm{H}_{2} \mathrm{O}$, respectively). Cumulative production of rose plants did not differ among substrate mixtures. Productivity significantly differed among flower stem classes. Stem class I $(>70 \mathrm{~cm})$ and class $\mathrm{V}(\leq 30 \mathrm{~cm})$ exhibited the least production, contributing to only 7.6 and $3.7 \%$ of the total production, respectively. The highest productivity was observed in classes III (51-
\end{abstract}


$60 \mathrm{~cm})$ and IV (31-50 cm), contributing to the bulk of productivity $(68.4 \%)$. Class II contributed a $20.3 \%$ of the production. Results showed that zeolite and perlite acted as inert materials. Zeolite did not exert any positive effect on productivity, in contrast to what has been reported in literature recently. Use of perlite resulted in a little improvement in photosynthesis, however this improvement was not reflected by a significant increase in production.

Keywords: Madelon rose, soil-less substrate, zeolite, perlite, gas exchange

\section{Introduction}

Soil-less cultures have been successfully used for several decades with the aim to intensify production and reduce cost (Maloupa et al., 1992). Cultivation of roses in various soil-less media is being achieved with promising commercial potentials. Roses have been produced in almerian sand culture, nutrient flow cultures (Takano, 1988), gravel culture (Sarro et al., 1989), volcanic materials (Raviv et al., 1999), organic substrates, mineral wool, aeroponics (Zieslin and Snir, 1989), rockwool (Kool and Van de Pol, 1991) and perlite (Katsoulas and Baille, 1999). The cost, local availability and experience in substrate use, are usually the determining factors for choosing a particular substrate type. Among the various soil-less culture practices, the use of substrate is the easiest to be adopted by growers.

Hydroponic cultivation in substrates containing zeolite has gained popularity in the last decade as an alternative to conventional soil-less production. Zeolite is reported to increase yields in several crops, i.e. wheat, eggplant, carrot, tomatoes, peppers (Mumpton, 1999). In floriculture, Issa et al. (2001) reported that gerbera performed better on zeolites than on perlite or rockwool. Zeolites are crystalline, hydrated alumino-silicate of alkali and alkaline earth cations, with an open three-dimensional structure, a unique adsorption capacity, and a high cation exchange and dehydration-rehydration ability (Mumpton, 1999). In contrast to the majority of production media which have a limited nutrient retaining capacity (Williams and Nelson, 1997), zeolite with its high cation exchange capacity (2-4 mequiv. $\mathrm{g}^{-1}$ ), has the potential to be used in soil-less media as a slow release nutrient source, positively affecting yields.

Perlite on the other hand has been widely used in soil-less cultures. Perlite, an alumino-silicate of volcanic origin, is rather inert (low buffering and cation exchange capacities of $0-1 \mathrm{mg} \mathrm{L}^{-1}$ ). In general, it has a closed cellular structure, with the majority of water being retained superficially and released slowly at a relatively low tension, providing excellent drainage of the medium and aeration of rhizosphere. Therefore, it requires frequent irrigation to prevent a fast developing water stress (Maloupa et al., 1992). Perlite also contains $6.9 \%$ aluminum which at low $\mathrm{pH}$ may be released into the solution and adversely affect the plants.

Because of their complementary properties, zeolite and perlite might be used together in substrates for soil-less cultivation and could potentially provide optimum growth conditions for roses. To test this hypothesis, we have studied the physiology, productivity, growth and flower quality of Madelon roses grown in zeolite (z) and perlite (p) substrates at various ratios (25z:75p, 50z:50p, 75z:25p and 100z:0p) in a climate and drip fertigation controlled greenhouse. 


\section{Materials and methods}

\subsection{Growth conditions}

Madelon rose plants grafted on rootstock of Rosa indica var. major were grown in a climate-controlled greenhouse (Agricultural Research Center of Macedonia and Thrace, Thessaloniki, Greece). Plants were transplanted in January, into $71 \mathrm{~L}$ black inside and white outside polyethylene bags ( $2 \mathrm{~m}$ length, $60 \mathrm{~cm}$ perimeter, $19 \mu \mathrm{m}$ thickness). Bags were filled with zeolite:perlite mixtures with ratios of 25z:75p, 50z:50p, 75z:25p and 100z:0p (v/v). Particle sizes of zeolite and perlite were 3-6 mm and 3-5 mm, respectively.

Sixteen slabs placed on 16 PVC gullies were formed and supported by polystyrene blocks placed $30 \mathrm{~cm}$ above the ground. Each slab represented one treatment, each treatment was replicated 4 times and carried 16 plants (total of 64 plants/treatment). Plants were spaced $12 \mathrm{~cm}$ apart. The rate of the irrigation (fertigation) was electronically controlled to obtain an average of $30 \%$ drainage. Irrigation was applied between 8 and 16 times per day for 10 to $20 \mathrm{~min}$. The final concentrations in the nutrient solution (mequiv. $\mathrm{L}^{-1}$ ) were $9.6 \mathrm{~N}_{-N_{3}}{ }^{-}, 0.8 \mathrm{~N}^{-} \mathrm{NH}_{4}{ }^{+}, 4.0 \mathrm{~K}^{+}, 6.8 \mathrm{Ca}^{2+}, 1.6 \mathrm{Mg}^{2+}, 1.6 \mathrm{H}_{2} \mathrm{PO}_{4}{ }^{2-}$,

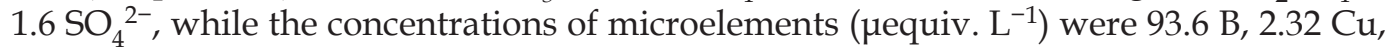
144.67 Fe, 2.02 Mn, 1 Mo, 11.4 Zn. The $\mathrm{pH}$ was adjusted to 5.8 with the addition of $65 \%$ $\mathrm{HNO}_{3}$ (this addition was taken into account when measuring the final N-concentration), and the electrical conductivity (EC) was $1.9 \mathrm{mS} \mathrm{cm}^{-1}$.

Winter and summer temperatures in the greenhouse were set at 13 and $25^{\circ} \mathrm{C}$, respectively. Summer temperatures were controlled using automatic fans and cooling system, and excessive radiance was controlled using a shading net applied in June. The shading net allowed a maximum photosynthetic active radiation (PAR) of 700-900 $\mu \mathrm{mol} \mathrm{m} \mathrm{m}^{-2} \mathrm{~s}^{-1}$. These PAR values were adequate to saturate photosynthesis in roses (Jiao et al., 1991). Yellow sticky traps, vaporized sulphur and spider mites predators (Ambliseious california and Phytoseiulus persimilis) were used in conjunction with Vendex and Pyrimor to control black and green aphids, white flies, spider mites and powdery mildew.

\subsection{Gas exchange measurements}

Seasonal oscillations in gas exchange were followed on a monthly basis from May (when rose production started) till September using a portable photosynthetic system (LI-6250, LI-COR Inc. Lincoln NE, USA). A fully developed, five-leaflet compound leaf (the fourth or fifth from the top of the flowering shoot) was chosen for the measurement. Three variables were determined: net photosynthetic rates $\left(A_{\text {net }^{\prime}} \mu \mathrm{mol} \mathrm{m}^{-2} \mathrm{~s}^{-1}\right)$, stomatal conductance $\left(g_{\mathrm{s}^{\prime}}\right.$ mol m $\left.\mathrm{m}^{-2} \mathrm{~s}^{-1}\right)$ and water use efficiency (WUE, $\mu \mathrm{mol} \mathrm{m} \mathrm{m}^{-2} \mathrm{~s}^{-1} \mathrm{CO}_{2} / \mathrm{mmol} \mathrm{m}^{-2} \mathrm{~s}^{-1}$ $\mathrm{H}_{2} \mathrm{O}$ ). Measurements were conducted on clear sunny days between $10 \mathrm{am}$ and $1 \mathrm{pm}$ (time of highest photosynthetic rates). Difference between air and leaf temperatures in the chamber were maintained close to air temperature (difference between 1 and $2{ }^{\circ} \mathrm{C}$ ) by manipulating the fan speed in the chamber. Vapor pressure deficit (VPD, mbar) between the leaf and the air was maintained near ambient (Awada et al., 2003). A total of 20 plants was selected per treatment (five plants per replication) for gas exchange measurements, the remaining plants were used for productivity measurements. 


\subsection{Flower production and quality measurements}

Flower production and quality were recorded between May and September in three flowering flushes (from May 9th to June 10th, June 11th to July 18th, and July 19th to September 7th). Stem length, thickness (at both top and bottom) and mass were measured. To evaluate quality, flowers were separated into five classes: class I (flowering stem length $>70 \mathrm{~cm})$, II $(61-70 \mathrm{~cm})$, III $(51-60 \mathrm{~cm})$, IV $(31-50 \mathrm{~cm})$, and class V $(\leq 30 \mathrm{~cm})$.

\subsection{Data analysis}

Repeated measures analyses of variance were performed using the Mixed Model Procedure in SAS statistical package to evaluate seasonal trends in gas exchange and the effect of substrate mixtures on gas exchange. Linear and/or quadratic contrast analyses for treatment (substrate mixture) effects were also performed. Treatment and month were considered fixed factors, while plants within replications were random (Steel et al., 1996). Rose productivity, stem width and weight were analyzed using the General Linear Model in SAS. Pairwise mean comparisons were performed using the probability of difference $(P=0.05)$ (Steel et al., 1996).

\section{Results}

\subsection{Gas exchange measurements}

Seasonal and diurnal trends of photosynthetic active radiation (PAR), air temperature (TA) and vapor pressure deficit (VPD) are presented in Figure 1. Environmental variables did not differ among treatments within sampling dates, and therefore, data were pooled together. There was a drop in total PAR received in July compared to June, due to the installation of the shading system. The lack of differences between treatments suggests that differences in gas exchange should be mainly attributed to differences in substrate characteristics and seasonality. Analysis of variance of repeated measurements over the 5-month period (May-September, Table 1) showed that roses exhibited significant sea-

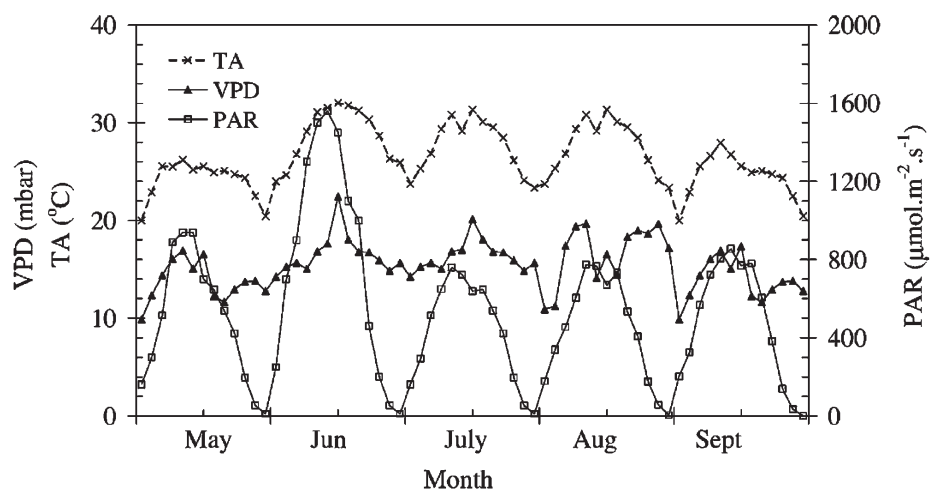

Figure 1. Average monthly course of photosynthetic active radiation (PAR, $\mu \mathrm{mol} \mathrm{m} \mathrm{m}^{-2} \mathrm{~s}^{-1}$ ), air temperature $\left(\mathrm{TA},{ }^{\circ} \mathrm{C}\right)$, and vapor pressure deficit (VPD, mbar) between 8:00 and 20:00 $\mathrm{h}$ in the greenhouse. 
Table 1. Analysis of variance of repeated measurements and orthogonal contrasts of seasonal changes (May-September)

\begin{tabular}{lccrr}
\hline Analysis of variance & d.f. & $A_{\text {net }}(F$-value $)$ & $g_{\mathrm{s}}(F$-value $)$ & WUE $(F$-value $)$ \\
\hline Month & 4 & $44.27^{* *}$ & $1.69 n s$ & $138.4^{* *}$ \\
Treatment & 3 & $2.54 n s$ & $0.67 n s$ & $7.55^{* *}$ \\
Treatment $\times$ month & 12 & $3.49^{* *}$ & $1.00 n s$ & $3.93^{* *}$ \\
& & & & \\
Orthogonal contrasts & & & & \\
$\quad$ 25z:75p vs. 50z:50p & 1 & $96.7^{* *}$ & $0.01 n s$ & $85.9^{* *}$ \\
25z:75p vs. 75z:25p & 1 & $95.3^{* *}$ & $3.21 n s$ & $17.2^{* *}$ \\
25z:75p vs. 100z:0p & 1 & $54.5^{* *}$ & $0.02 n s$ & $139.3^{* *}$ \\
50z:50p vs. 75z:25p & 1 & $2.55 n s$ & $3.6 n s$ & $42.9^{* *}$ \\
50z:50p vs. 100z:0p & 1 & $4.99^{*}$ & $0.01 n s$ & $443.6^{* *}$ \\
$75 z: 25 p$ vs. 100z:0p & 1 & $1.51 n s$ & $3.49 n s$ & $315.9^{* *}$ \\
25z:75p vs. (50z:50p, 75z:25p and 100z:0p) & 1 & $20.59^{* *}$ & $1.42 n s$ & $174.5^{* *}$ \\
\hline
\end{tabular}

Net photosynthesis $\left(A_{\text {net }} \mu \mathrm{mol} \mathrm{m} \mathrm{s}^{-2} \mathrm{~s}^{-1}\right)$, stomatal conductance $\left(g_{\mathrm{s}}, \mathrm{mol} \mathrm{m}^{-2} \mathrm{~s}^{-1}\right)$ and water use efficiency (WUE, $\mu \mathrm{mol} \mathrm{m} \mathrm{m}^{-2} \mathrm{~s}^{-1} \mathrm{CO}_{2} / \mathrm{mmol} \mathrm{m}^{-2} \mathrm{~s}^{-1} \mathrm{H}_{2} \mathrm{O}$ ) in hydroponic roses grown in four substrates (treatments) of zeolite:perlite (z:p) mixtures.

$n s$ denotes not significant at 0.05 .

${ }^{*}$ F-values significant at 0.05 .

** $F$-values significant at 0.01 .

sonality in net photosynthesis $\left(A_{\text {net }}\right)$, and that this trend in seasonality was to some extent influenced by substrate mixture treatments. More specifically, even though the overall $A_{\text {net }}$ rates (values ranging between 18.36 and $19.11 \mu \mathrm{mol} \mathrm{m}^{-2} \mathrm{~s}^{-1}$ ) were not significantly influenced by substrate treatment, orthogonal contrasts (Table 1) showed that trends in $A_{\text {net }}$ for roses grown in 25z:75p differed significantly from those grown in 50z:50p, 75z:25p and 100z:0p. Significantly higher $A_{\text {net }}$ values for roses grown in 25z:75p than in 100z:0p were observed in May, August and September (Figure 2A). These differences in $A_{\text {net }}$ were not reflected by differences in stomatal conductance. Stomatal conductance did not show any significant seasonality or trends in response to substrate mixtures, averaging $0.89 \mathrm{~mol} \mathrm{~m}^{-2} \mathrm{~s}^{-1}$ (Table 1, Figure 2B). Water use efficiency on the other hand, exhibited significant variability among treatments and seasons. Roses in 25z:75p mixtures had significantly lower WUE than roses in 100z:0p mixtures $(1.8 \pm 0.15$ and $2.0 \pm 0.13$, respectively). WUE in 50z:50p and 75z:25p mixtures averaged 1.9 and values were not significantly different from either 25z:75p or 100z:0p mixtures (Figure 2C).

\subsection{Production and quality}

Analysis of variance (Table 2) showed that cumulative production of rose plants $(n=10)$ did not differ among substrate mixtures. The average cumulative production per plant ranged from 50 to 55 for 100z:0p and 25z:75p substrate mixtures, respectively (Figure 3). Productivity significantly differed among classes (Table 2, Figure 3). Stem class I $(>70 \mathrm{~cm})$ and class $\mathrm{V}(\leq 30 \mathrm{~cm})$ exhibited the least production, averaging 4.1 and 2 flowers per plant and contributing to 7.6 and $3.7 \%$ of the total production, respectively. The highest productivity was observed in classes III $(51-60 \mathrm{~cm})$ and IV $(31-50 \mathrm{~cm})$, with $17(31.4 \%)$ and $20(37 \%)$ flowering stems per plant. Classes III and IV did not differ be- 

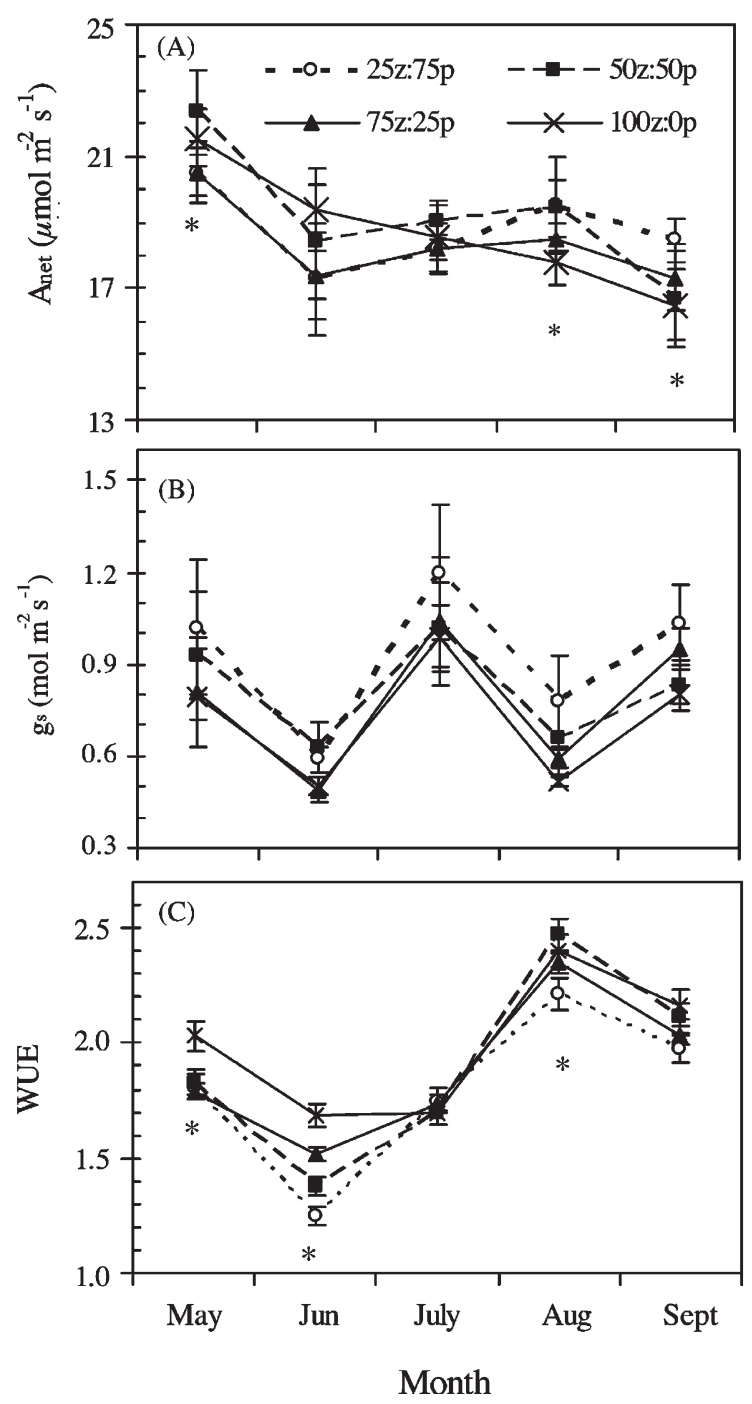

Figure 2. Seasonal variation of (A) net photosynthesis $\left(A_{\text {net' }} \mu \mathrm{mol} \mathrm{m}^{-2} \mathrm{~s}^{-1}\right)$, (B) stomatal conductance ( $\mathrm{gs}, \mathrm{mol} \mathrm{m}^{-2} \mathrm{~s}^{-1}$ ) and, (C) water use efficiency (WUE, $\mu \mathrm{mol} \mathrm{m} \mathrm{m}^{-2} \mathrm{~s}^{-1}$ of $\mathrm{CO}_{2} / \mathrm{mmol} \mathrm{m}^{-2} \mathrm{~s}^{-1}$ of $\mathrm{H}_{2} \mathrm{O}$ ) and respective standard error bars in hydroponic roses, grown in four zeolite:perlite (z:p) mixtures in the greenhouse. An asterisk indicates significant differences between treatments within a month at $P=0.05, n=20$.

tween each other, but differed significantly from the remaining classes. They contributed to the bulk of the production with $70 \%$ of the total. Class II contributed to an average of 11 flowering stems per plant, or $20.3 \%$ of total production.

Stem width at the top and base, and average mass did not differ among substrate treatments (Table 2), therefore data were pooled together (Figure 4). Stem width and weight declined, as expected, significantly with decline in stem length (classes I-V). The decline was steeper, mass and width-wise, at the base than with the width at top. The latter was the least affected by the decline in stem length. 
Table 2. Analysis of variance table of stem production

\begin{tabular}{lccccc}
\hline $\begin{array}{l}\text { Analysis of } \\
\text { variance }\end{array}$ & d.f. & $\begin{array}{c}\text { Production } \\
(F \text {-value })\end{array}$ & $\begin{array}{c}\text { Width }(\mathrm{T}) \\
(F \text {-value })\end{array}$ & $\begin{array}{c}\text { Width }(\mathrm{B})(\mathrm{T}) \\
(F \text {-value })\end{array}$ & $\begin{array}{c}\text { Weight }(\mathrm{T}) \\
(F \text {-value })\end{array}$ \\
\hline Class & 4 & $95.6^{* *}$ & $145.6^{* *}$ & $305.3^{* *}$ & $518.4^{* *}$ \\
Treatment & 3 & $0.06 n \mathrm{~ns}$ & $2.24 \mathrm{~ns}$ & $0.28 \mathrm{~ns}$ & $0.86 \mathrm{~ns}$ \\
Class $\times$ treatment & 12 & $0.17 \mathrm{~ns}$ & $1.16 \mathrm{~ns}$ & $1.13 \mathrm{~ns}$ & $1.42 \mathrm{~ns}$ \\
\hline
\end{tabular}

Stem width at the top (T) and base (B), and stem weight in five stem length classes (I-V) of hydroponic roses, grown in four zeolite:perlite mixtures (treatments).

$n s$ denotes not significant at 0.05 .

** F-values significant at 0.01 .

\section{Discussion}

Data on the physiology of roses, including water use and photosynthesis and their impact on growth and yield, are either scarce (Jiao and Grodzinski, 1998) or unreliable (Raviv and Blom, 2001). The importance of radiation and temperature on the other hand, has been studied by Zieslin and Mor (1990) and Jiao et al. (1991) among others. Jiao et al. (1991) reported that irradiance accounts for $70 \%$ of the total variability in assimilation rate in roses. A decrease in light intensity below the saturation point due to either seasonal changes or shading is believed to reduce yield in roses (Zieslin and Mor, 1990). In the Mediterranean area, however, the high light intensity during summer reduces yield and flower quality in the greenhouse due to its direct effect on temperature, relative humidity and the resulting vapor pressure deficit, transpiration and stomatal conductance (Bredmose, 1993). Decreased length and mass of rose stems following supplementary lighting have been reported (Jiao et al., 1988). Partial shading and greenhouse ventilation are therefore, common practices in this region in an effort to decrease temperature, reduce vapor pressure deficit, and to control insects and diseases.

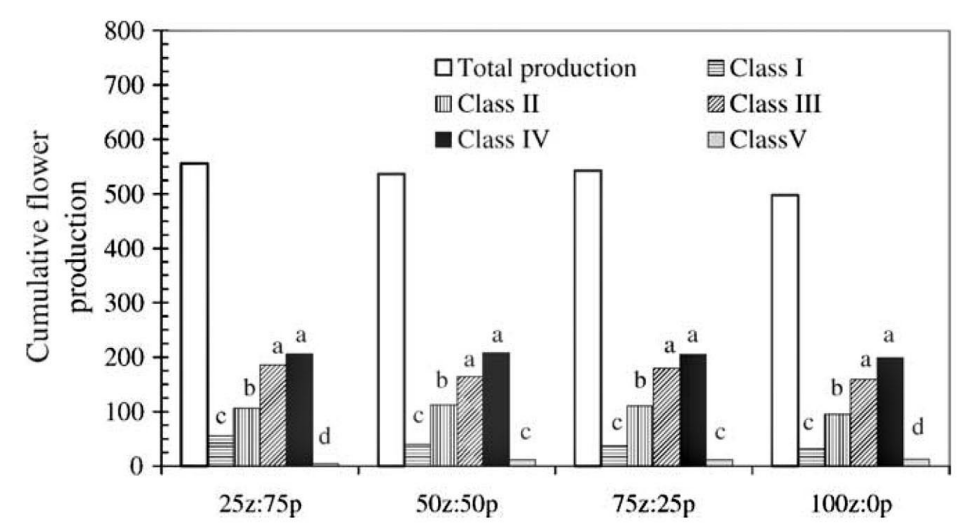

Figure 3. Cumulative flower production of hydroponic roses $(n=10$ plants) in five stem classes (I$\mathrm{V})$, grown in four zeolite:perlite (z:p) mixtures in the greenhouse. All treatments (25z:75p, 50z:50p, 75z:25p and 100z:0p) within the same class are not statistically different at $P=0.05$. Means with the same letter within a treatment are not statistically different at $P=0.05$. 


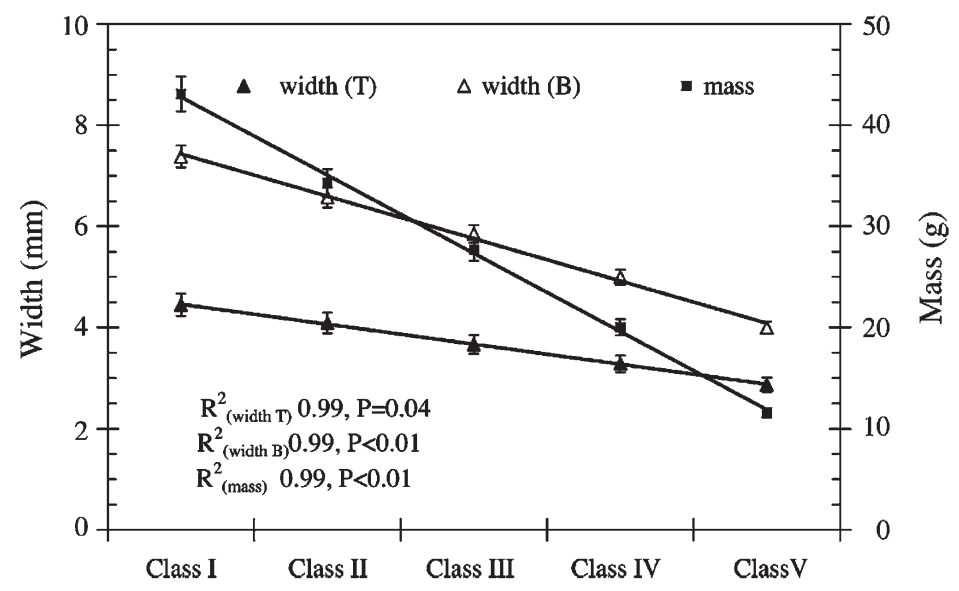

Figure 4. Overall average and respective standard error bars of stem width at the base (B) and top (T) and corresponding stem mass in five classes (I-V) of hydroponic roses.

Photosynthetic rates for rose leaves have been reported to range from $6.9 \mu \mathrm{mol} \mathrm{m} \mathrm{m}^{-2} \mathrm{~s}^{-1}$ for the "Forever yours" (Aikin and Hanan, 1975) to $13 \mu \mathrm{mol} \mathrm{m}{ }^{-2} \mathrm{~s}^{-1}$ for "Samantha" cultivar (Bozarth et al., 1982). Aikin and Hanan (1975) and Bozarth et al. (1982), reported that photosynthesis reached the point of saturation at $450-500 \mu \mathrm{mol} \mathrm{m}^{-2} \mathrm{~s}^{-1}$. Maximum rates reported in the current study (18.36 and $19.11 \mu \mathrm{mol} \mathrm{m}^{-2} \mathrm{~s}^{-1}$, PAR 700$900 \mu \mathrm{mol} \mathrm{m} \mathrm{m}^{-2} \mathrm{~s}^{-1}$ ) are consistent with those reported by other authors for outdoor-growing rose plants (e.g. Lieth and Pasian, 1990). Net photosynthesis was higher and WUE was lower in 25z:75p than in 100z:0p on several sampling dates. It is known that plants under increasing water stress respond by an increase in WUE. In the current study, the observed trend of a lower WUE in 25z:75p substrate suggests that roses in this media had more readily available water than roses in 100z:0p. Both substrates (zeolite and perlite) were coarse, however, during establishment (bag filling and transplanting, and cultivation periods, an alteration (fragmentation) of perlite material usually occurs (Orozco and Marfa, 1995). Zeolite, though subjected to the same procedure, is usually not affected because of its hardness. Consequently, the 25z:75p substrate was altered the most, resulting in the presence of particles with sizes smaller than $3 \mathrm{~mm}$ in the medium. The latter is believed to decrease the percentage of pores with large diameters $(60 \mu \mathrm{m})$, containing the gravitational water that is easily drained, and to increase the percentage of those with a diameter between 30 and $60 \mu \mathrm{m}$. Consequently, an increase in the total available water content of the growing media occurred, improving water status, resulting in a better water and nutrient uptake, and avoiding a pronounced midday water stress. These favorable conditions in the 25z:75p media resulted in a slight, but not significant, increase in rose productivity compared to the other treatments.

First flush in flower production was observed in May, 4 months after planting. Productivity did not significantly differ among treatments. Similar observations were reported in the literature for other rose cultures (Brun and Tramier, 1988). Production and quality results indicated that particle size of coarse zeolite (3-5 mm) and perlite (3$6 \mathrm{~mm}$ ) ensured sufficient aeration in all four growing media (Maloupa et al., 1992; Issa 
et al., 2001). The fertigation management and the cultural practices implemented (open hydroponics system) lead both substrates to react as inert materials, therefore, imposing no direct effects on nutrient availability in the rhizosphere. Results on positive effects of zeolite on productivity reported in the literature (e.g. Mumpton, 1999; Issa et al., 2001) may be explained by the powdery form of zeolite material used, which provided a higher surface available for absorption and cation exchange and/or by the fertilization management applied. We conclude that coarse zeolite in soil-less cultures simply acts as an inert material and does not exert any positive effect on productivity. The use of perlite, on the other hand, resulted in some photosynthetic improvement which, however, was not reflected by a significant increase in productivity.

\section{Acknowledgments}

The authors thank the Mediterranean Agronomic Institute of Chania-Crete, Greece, for partially financing this work. We also appreciate the comments of the reviewers for Scientia Horticulturae, which helped improve the final manuscript.

\section{References}

Aikin and Hanan, 1975 W. J. Aikin and J. J. Hanan, Photosynthesis in the rose: Effect of light intensity, water potential and leaf age, J. Am. Soc. Hort. Sci. 100 (1975), pp. 551-553.

Awada et al., 2003 T. Awada, K. Radoglou, M. F. Fotelli, and H.-I. A. Constantinidou, Ecophysiology of seedlings of three Mediterranean pine species in contrasting light regimes, Tree Physiol. 23 (2003), pp. 33-41.

Bozarth et al., $1982<$ C. S. Bozarth, R. A. Kennedy and K. A. Schekel, The effects of leaf age on photosynthesis in roses, J. Am. Soc. Hort. Sci. 107 (1982), pp. 707-712.

Bredmose, $1993 \varangle \mathrm{N}$. Bredmose, Effects of year-round supplementary lighting on shoot development, flower and quality of two glasshouse rose cultivars, Sci. Hort. 54 (1993), pp. 69-85.

Brun and Tramier, $1988<\mathrm{R}$. Brun and P. H. Tramier, Culture du rosier sur laine de roche, P.H.M. Rev. Hort. 289 (1988), pp. 43-51.

Issa et al., 20014 M. Issa, G. Ousounidou, H. Maloupa, and H. A. Constantinidou, Seasonal and diurnal photosynthetic responses of two gerbera cultivars to different substrates and heating systems, Sci. Hort. 88 (2001), pp. 215-234.

Jiao and Grodzinski, $1998<$ J. Jiao and B. Grodzinski, Environmental influences on photosynthesis and carbon export in greenhouse roses during development of flowering shoot, J. Am. Soc. Hort. Sci. 123 (1998), pp. 1081-1088.

Jiao et al., $1988<$ J. Jiao, M. J. Tsujita, and R. G. Dutton, Phase I-Environmental parameters for computer-controlled greenhouses; Phase II-Temperature for roses as influenced by light levels, Roses Inc. Bull. (1988) (January), pp. 83-93.

Jiao et al., $1991<$ J. Jiao, M. J. Tsujita and B. Grodzinski, Influence of radiation and $\mathrm{CO}_{2}$ enrichment on whole plant net $\mathrm{CO}_{2}$ exchange in roses, Can. J. Plant Sci. 71 (1991), pp. 245-252.

Katsoulas and Baille, 1999 K. C. N. Katsoulas and A. Baille, Transpiration and canopy resistance of greenhouse soilless roses: measurements and modelling, Acta Hort. 507 (1999), pp. 61-68. 
Kool and Van de Pol, 19914 M. T. N. Kool and P. A. Van de Pol, The rose cultivar Madelon on rockwool. The rootstock has a considerable influence on flower yield, Vakblad voor de Bloemisterij 46 (1991), pp. 62-64.

Lieth and Pasian, $1990<\mathrm{J}$. H. Lieth and C. C. Pasian, A model for net photosynthesis of rose leaves as a function of photosynthetically active radiation, leaf temperature, and leaf age, $J$. Am. Soc. Hort. Sci. 115 (1990), pp. 486-491.

Maloupa et al., 1992 E. Maloupa, I. Mitsios, P. F. Martinez, and S. Bladenopoulou, Study of substrate use in Gerbera soilless culture grown in plastic greenhouses, Acta Hort. 323 (1992), pp. 139-144.

Mumpton, $19994 \mathrm{~F}$. A. Mumpton, La roca magica: Uses of natural zeolites in agriculture and industry, Proc. Natl. Acad. Sci. U.S.A. 96 (1999), pp. 3463-3470.

Orozco and Marfa, $1995 \varangle$ R. Orozco and O. Marfa, Granulometric alteration, air-entry potential, and hydraulic conductivity in perlites used in soilless cultures, Acta Hort. 408 (1995), pp. 147-161.

Raviv and Blom, 20014 M. Raviv and T. J. Blom, The effects of water availability on photosynthesis and productivity of soilless-grown cut roses, Sci. Hort. 88 (2001), pp. 257-276.

Raviv et al., $1999 \varangle$ M. Raviv, R. Wallach, A. Silber, S. Medina, and A. Krasnovsky, The effects of hydraulic characteristics of volcanic materials on yields of roses grown in soilless culture, J. Am. Soc. Hort. Sci. 124 (1999), pp. 205-209.

Sarro et al., 1989 M. J. Sarro, M. J. Sanchez, C. Miyar, and P. Zornoza, Nutritional requirements of two rose cultivars grown in gravel culture, Acta Hort. 246 (1989), pp. 219-222.

Steel et al., $1996<$ R. G. Steel, D. A. Dickey, and J. H. Torrie, Principles and Procedures of Statistics: A Biometrical Approach, McGraw-Hill College (1996) pp. 672.

Takano, $1988<\mathrm{T}$. Takano, Effect of conductivity and temperature of nutrient solution on the mineral nutrition of horticultural crops in water culture, Acta Hort. 230 (1988), pp. 299-302.

Williams and Nelson, $1997 \varangle \mathrm{K}$. A. Williams and P. V. Nelson, Using precharged zeolite as a source of potassium and phosphate in a soilless container medium during potted chrysanthemum production, J. Am. Soc. Hort. Sci. 122 (1997), pp. 703-707.

Zieslin and Mor, $1990<$ N. Zieslin and Y. Mor, Light on roses. A review, Sci. Hort. 43 (1990), pp. 1-14.

Zieslin and Snir, 19894 N. Zieslin and P. Snir, Responses of rose plants cultivar 'Sonia' and Rosa indica major to changes in $\mathrm{pH}$ and aeration of the root environment in hydroponic culture, Sci. Hort. 37 (1989), pp. 339-349. 